\title{
Correction to: Thymectomy and Risk of Generalization in Patients with Ocular Myasthenia Gravis: a Multicenter Retrospective Cohort Study
}

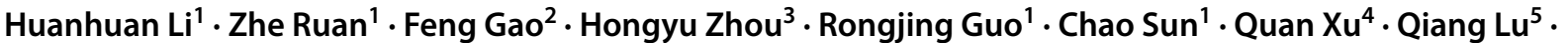

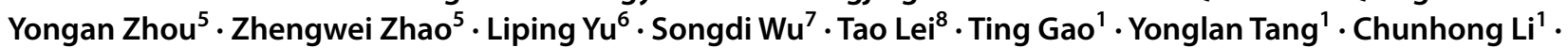 \\ Feiyan Huo ${ }^{1} \cdot$ Ying Zhu $^{1}$ - Jie Sun ${ }^{1}$. Baoli Tang ${ }^{1} \cdot$ Min Zhang $^{1} \cdot$ Yanwu Gao ${ }^{1} \cdot$ Xiaodan Lu$^{1} \cdot$ Zhuyi Li $^{1} \cdot$ Ting Chang $^{1}$
}

Published online: 8 November 2021

(c) The American Society for Experimental NeuroTherapeutics, Inc. 2021

\section{Correction to: Neurotherapeutics (2021) https://doi.org/10.1007/s13311-021-01129-z}

In this article, the affiliation details for the authors were corrected.

The original article has been corrected.

Publisher's Note Springer Nature remains neutral with regard to jurisdictional claims in published maps and institutional affiliations.

The original article can be found online at https://doi.org/10.1007/ s13311-021-01129-z.

Zhuyi Li

lizhuyiafu@163.com

$\triangle$ Ting Chang changting1981@163.com

1 Department of Neurology, Tangdu Hospital, the Fourth Military Medical University, 569 XinSi Road, Xi' an 710038, China

2 Department of Neuroimmunology, Henan Institute of Medical and Pharmaceutical Sciences, Zhengzhou University, Zhengzhou, China

3 Department of Neurology, West China Hospital, Sichuan University, Chengdu, China
4 Department of Thoracic Surgery, Jiangxi Provincial People's Hospital Affiliated To Nanchang University, Nanchang, China

5 Department of Thoracic Surgery, Tangdu Hospital, the Fourth Military Medical University, Xi' an, China

6 Department of Neurology, Xianyang First People's Hospital, Xianyang, China

Department of Neurology, Xi' an No.1 Hospital, Xi'an, China

8 Department of Neurology, Xi' an Fourth Hospital, Xi' an, China 